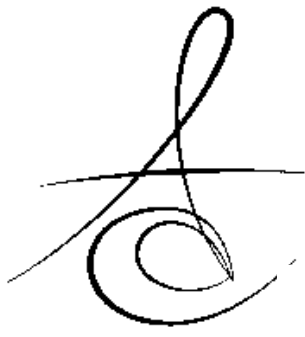

Yrd. Doç. Dr. Burak DOĞAN*

\section{PERİODONTAL TEDAVİDE YENİ YAKLAŞIM: İLERİ BASAMAK ÇÖZÜCÜ LİPİD MEDYATÖRLERI}

\section{A NEW APPROACH IN PERIODONTAL TREATMENT: PRORESOLVING LIPID MEDIATORS}

Yrd. Doç. Dr. Esra Sinem KEMER DOĞAN* Prof. Dr. Behiye BOLGÜL**

\author{
Makale Kodu/Article code: 2533 \\ Makale Gönderilme tarihi: 29.12.2015 \\ Kabul Tarihi: 18.03.2016
}

\section{öz}

Sağlığın devam ettirilebilmesi için akut enflamatuvar yanıtın tamamen çözülmesi ve vücudun homeostazise dönmesi gerekmektedir. Enflamatuvar yanıtta rol alan lökositlerin, ortamda ölü hücre ve ürünlerini bırakmayacak şekilde kaldırıması ideal sonuç olmakla birlikte periodontal hastalıta ve birçok farklı sistemik hastalıkta, benzer şekilde kontrol altına alınamayan ve çözülememiş bir enflamatuvar durumun oluştuğu görülmektedir.

Bugüne kadar çalışılan antienflamatuvar ajanlardan steroidler, steroid olmayan antienflamatuvar ilaçlar ve antihistaminikler, akut enflamatuvar yanıtın başlamasında rol alan anahtar proenflamatuvar medyatör yollarını bloke ederler ve enflamasyonun kardinal bulgularının kontrolünde rol almaktadırlar. Bu terapötik yaklaşım, birçok enflamatuvar hastalığın tedavisinde temel konumda yer alsa da beraberinde oluşan yan etkilerin de göz ardı edilmemesi gerektiği bir gerçektir. Son yıllarda, enflamasyonla ilişkili moleküler temellerin ortaya konulmasıyla birlikte, enflamasyonun çözülmesinin aktif ve agonist ilişkili bir süreç olduğu ve doku homeostazisine dönüşün çok dikkatli bir şekilde düzenlendiği anlaşılmışıı. Enflamasyonun çözülmesinin yeni bir sınıf olan ileri basamak çözücü lipid medyatörleri (İBÇLM) tarafından düzenlendiğinin anlaşılmasıyla birlikte, periodontal patolojinin önlenmesinde ve enflamatuvar lökositlerin eliminasyonunda, İBÇLM moleküllerinin potansiyel kullanımlarına olan ilginin arttığı görülmektedir.

Bu derlemede, İBÇLM'lerin enflamatuvar süreçte ve periodontal hastalık patogenezindeki önemi ortaya konulmaya çalışılmışır.

Anahtar sözcükler: Periodontal hastalıklar,

\section{ABSTRACT}

Complete resolution of acute inflammatory response and returning the body to homeostasis is crucial for on-going health. Although removing of leukocytes in inflammation area without leaving any dead cells or their products behind is an ideal result, it appears that uncontrolled and unresolved inflammatory condition occurs in periodontal disease and various systemic diseases similarly.

Most of the antiinflammatory agents studied up to now such as steroids, non-steroid antiinflammatory drugs and antihistamines bloke key proinflammatory mediator ways in the initiation of acute inflammatory response or take part in the control of the cardinal symptoms. Despite this therapeutic approach is a basic principle for the treatment of many inflammatory diseases, it's clear that adverse effects should not be ignored.

Recently, after the determination of the inflammatory basics, we understood that inflammatory resolution is an active and agonist related process and returning to the tissue homeostasis is arranged very carefully. Together with the understanding of the inflammatory resolution is arranged by new classification of proresolving lipid mediators (PRLMs), the interest on these molecules related to the prevention of periodontal pathology and elimination of inflammatory leukocytes have increased.

In this review, we aimed to put forward the importance of the PRLMs on the inflammatory process and periodontal pathogenesis.

Keywords: Periodontal diseases, inflammation, fatty acids

\footnotetext{
${ }^{*}$ Mustafa Kemal Üniversitesi, Diş Hekimliği Fakültesi, Periodontoloji A D

${ }^{* *}$ Mustafa Kemal Üniversitesi, Diş Hekimliği Fakültesi, Pedodonti A D
} 


\section{GİRIŞ}

Periodontal hastalıklar, mikrobiyal etiyolojik faktörlerin konak yanıtını başlatması ve indüklemesiyle devam eden enflamatuvar süreçleri kapsamaktadır. ${ }^{1}$ Periodontal hastalıkla birlikte diyabet, Alzheimer, kardiyovasküler hastalıklar ve kanserlerde kontrol altına alınamayan ve çözülememiş bir enflamatuvar durumun oluştuğu görülmektedir. ${ }^{2-4}$

Son yıllarda, enflamasyonla ilişkili moleküler temellerin ortaya konulmasıyla birlikte, enflamasyonun çözülmesinin aktif ve agonist ilişkili bir süreç olduğu ve doku homeostazisine dönüşün çok dikkatli bir şekilde düzenlendiği anlaşılmıştır. Enflamasyonun çözülmesinin yeni bir sınıf olan "proresolving lipid medyatörleri" ya da "ileri basamak çözücü lipid medyatörler (İBÇLM)" tarafından düzenlendiğinin anlaşılmasıyla birlikte, periodontal patolojinin önlenmesinde ve enflamatuvar lökositlerin eliminasyonunda, İBÇLM moleküllerine olan ilginin arttığı aşikardır. ${ }^{5,6}$

Periodontal hastalıkla ilişkili patogenez basamakları düşünüldüğünde, periodontal hastalıkların oluşumunun engellenmesi ve tedavisinde, ana hedefin enflamatuvar sürecin hiperenflamatuvar sürece geçişinin önlenmesi olduğu bilinen bir gerçektir. ${ }^{7}$ Enflamasyonun çözülmesinde kullanılan antienflamatuvar terapötik yaklaşım, birçok enflamatuvar hastalığın tedavisinde temel konumda yer alsa da beraberinde oluşan yan etkilerin de göz ardı edilmemesi gerektiği unutulmamalıdır. ${ }^{8,9}$ Enflamasyonun ileri aşamalarında, omega ( $\omega)-3$ ve $\omega-6$ esansiyel yağ asitlerinin metabolize olmasıyla oluşan lipoksin (LX), rezolvin (Rv), protektin (PD) ve son olarak keşfedilen maresin (MaR)'lar, endojen İBÇLM'ler olarak tanımlanmaktadır. $\mathrm{Bu}$ moleküller, lökositlerin ölümü ile birlikte monositik hiperenflamatuvar fenotipe geçişi engellemektedirler. ${ }^{10}$

\section{Güncel Durum}

Enflamasyonun Çözülmesiyle İlişkili

Geleneksel olarak proenflamatuvar medyatörlerin katabolize olmasıyla enflamasyonun sonlandırılacağı düşünülmekteyken, günümüzde çözülmenin farklı hücresel olaylar ve endojenöz kimyasal medyatörler tarafından aktif olarak yürütüldüğü görüşü öne çıkmaktadır. ${ }^{11}$ Enflamasyonun çözülmesi sırasında 1. Polimorfonükleer lökosit (PMNL) infiltrasyonu durur; 2. Vasküler permeabilite ve ödem normale döner; 3. PMNL'ler çoğunlukla apopitozise uğrayarak bölgeyi terk eder; 4. Monositler/makrofajlar bölgeye infiltre olur; 5. Makrofajlar apoptotik PMNL artıklarını, yabancı mikroorganizma/ajanları ve nekrotik debrisi temizler. ${ }^{12,13}$

Enflamasyonun başlangıcında prostaglandin (PG)'ler ve lökotrienler gibi medyatörlerin üretilmesiyle kardinal bulgular açığa çıkmaktadır. Daha sonra $\mathrm{PGE}_{2}$ ve $\mathrm{PGD}_{2}$ tarafından, ileri basamak çözücü özellikleriyle birlikte antienflamatuvar etki de gösterebilen $L X, R v$ ve PD gibi İBÇLM'lerin üretilmesi indüklenmektedir. ${ }^{14,15}$ İBÇLM'ler, makrofajların fagositozunu stimüle ederken diğer taraftan enflame dokuda PMNL infiltrasyonunu azaltırlar. Ayrıca mukozal epitelyal hücrelerin antimikrobiyal aktivitelerini de arttırırlar. ${ }^{16}$

Kontrol edilemeyen bir enflamatuvar sürecin; doku hasarı, kronik enflamasyon, skar ve fibrozisle sonuçlanacağı öngörüsü geniş bir çevre tarafından kabul edilmektedir. ${ }^{17}$ Kontrolsüz bir konak yanıtı ise, PMNL aracılı doku yaralanması, geri dönüşümsüz organ hasarı ve ilişkili majör sağlık problemlerine yol açmaktadır. PMNL'lerin atipik ya da uzamış aktivasyonlarının, birçok kronik hastalıkta görülen doku hasarına yol açabileceği gösterilmiştir. ${ }^{18}$

\section{IBBCLM'Ierle Enflamasyonun Çözülmesi}

Balık yağında zengin bir şekilde bulunan $\omega-3$ ve $\omega-6$ olarak tanımlanan iki tip esansiyel çoklu doymamış yağ asiti (ÇDYA); enflamasyon, renal fonksiyonlar, hemodinamik ve pıhtılaşma gibi birçok hücresel fonksiyon için kritik öneme sahiptir. $\omega-6$ ve $\omega-3$ esansiyel yağ asitlerinin metabolize olmasıyla araşidonik asit (AA)'dan oluşan LX'lerle, eikozapentaenoik asit ve dokozahekzaenoik asitten oluşan Rv, PD ve MaR'lar adı altında yeni tür İBÇLM'ler tanımlanmıştır. Rv ve PD'lerin, insanlarda görülen hastalıkların enflamasyonla ilişkili hayvan modellerinde (peritonitis, dermal enflamasyon, astım, oküler hastalıklar vs.) oldukça potent etkilerinin olduğu yapılan çalışmalarda gösterilmiştir. ${ }^{14,19}$

LX'ler, AA'nın, 15-hidroperoksieikozatetraenoik asite (HPETE), 15-lipoksijenaz (LOX) aracılı dönüşümü sonrasında sentezlenirler ve iki ayrı izomeri keşfedilmiştir: LXA4 ve LXB4. İBÇLM'lerden LX'ler, hem antienflamatuvar etkileri hem de ileri basamak çözücü özellikleriyle çift etki gösterebilen ilk medyatörler olarak tanımlanmıştır. ${ }^{6}$ Enflamasyonun doğal seyri sırasında lipid medyatör profili, proenflamatuvar eikazanoidlerden LX'lere kayarken, $\mathrm{PGE}_{2}$ ve $\mathrm{PGD}_{2}, 15$-LOX sentezini stimüle eder. Siklooksijenaz (COX) türevi proenflamatuvar eikazanoidler, antienflamatuvar lipid 
medyatörlerinin sürekli üretilmesinde kritik pozisyondadır ve COX-2'nin inhibe edilmesinin enflamasyonun çözülmesini geciktirdiği ifade edilmektedir. ${ }^{20}$

LX'ler ve 15-epi-lipoksinler, makrofajlar tarafindan apoptotik PMNL fagositozunu stimüle ederler. LX'ler aynı zamanda interlökin (IL)-10 gibi antienflamatuvar sitokin üretimini de arttırarak bölgeye daha fazla lökosit infiltrasyonunu engellemekle kalmayıp mevcut lökositlerin ortamdan uzaklaştırımasına da katkı sağlamaktadırlar. ${ }^{12}$ LX'lerin diğer etkileri arasında nükleer faktör kappa B aktivasyonunun inhibisyonu, lökotrien biyosentezinin önlenmesi, süperoksit üretiminin azaltılması ve lökosit kemotaksisinin düzenlenmesi yer almaktadır. ${ }^{21}$

Enflamasyonun başlangıç aşamasında bölgeye göç eden PMNL'ler, mikroorganizma ve ürünlerini fagosite ettikten sonra apopitozise uğrarlar. PMNL'lerin daha sonra gelen makrofajlar tarafindan temizlenmesi esnasında İBÇLM'ler, lokal proenflamatuvar sinyalleri engellerler ve bölgeye daha fazla PMNL infiltrasyonunu, dolayısıyla PMNL aracılı doku yıkımını azaltarak antienflamatuvar etki gösterirler. ${ }^{12}$ Antienflamatuvar medyatörler, fagositoz basamağına etki etmezlerken İBÇLM'ler, ayrıca makrofajlar tarafından PMNL ve ölü hücrelerin fagositozunu da arttırarak enflamasyonun çözülmesini hızlandırmaktadırlar. Bu yeni medyatörlerin etki mekanizmalarındaki temel farklılık sayesinde, enflamasyonun aktif çözülmesinde yeni bir kapı açılıışır.

\section{İBÇLM'ler ve Periodontal Hastalık}

Periodontitis patogenezi IL-1, IL-6, IL-8, PGE 2 ve tümör nekroz faktör-a gibi sitokinler, kemokinler ve matriks metalloproteinaz (MMP)-1 ve MMP-8 gibi metalloproteinazlar tarafından düzenlenmektedir. Periodontal hastalığa sahip bireylerde dişeti oluğu SIVISI (DOS)'ta tespit edilen PGE ${ }_{2}^{\prime}$ nin en temel kaynaklarından birisi PMNL'lerdir. ${ }^{22,23}$ Lökosit infiltrasyonu üzerine yapılan in vivo bir çalışmada Porphyromonas gingivalis ( $P$. gingivalis)'in COX-2 üzerinden $\mathrm{PGE}_{2}$ seviyelerini arttırarak yoğun PMNL akışını uyardığı gösterilmiştir. ${ }^{24}$

P. gingivalisín in vitro trombosit agregasyonunu tetikleyerek tromboembolik olaylara katkı sağlayabileceği ortaya konulmuştur. ${ }^{25,26}$ Diğer taraftan, $P$. gingivalis ile indüklenen trombosit/lökosit agregasyonunun ve reaktif oksijen türleri (ROT) üretiminin, LXA4 ile inhibe edilebileceği de ifade edilmektedir. ${ }^{27} P$. gingivalis'e karşı PMNL yanıtında lipid medyatörlerinin rolünün araştırıldığı bir diğer çalışmada ise, stabil LX analogları ve aspirinle tetiklenmiş LX uygulamasının, PMNL infiltrasyonunu azalttığı ve enfeksiyonun yayılmasına izin vermeden $\mathrm{PGE}_{2}$ seviyelerini düşürdüğü belirtilmektedir. Bu sonuçlar ışığında LX'lerin PMNL'lerin göçünü engelleyerek ve PMNL aracılı doku yıkımını sınırlandırarak periodontitiste koruyucu rollerinin bulunduğu bildirilmektedir. ${ }^{24}$

Artmış LX üretimi hipoenflamatuvar fenotiple ilişkili olduğu için, ligatürle indüklenen periodontitis modelinde, topikal olarak LXA4 analoğu uygulaması sonrasında lökosit infiltrasyonu önemli ölçüde azalmış, kemik kaybında ve enflamasyonda baskılanma görülmüştür. Bu sonuçlardan yola çıkılarak çözülmenin aktif bir süreç olduğu ve periodontitis ile ilişkili doku yıkımında, enflamasyonun sorumlu olduğu ortaya konulmuştur. ${ }^{28} \mathrm{Bu}$ bulgular, periodontitis ve artritis gibi enflamasyon ve kemik kaybının görüldüğü hastalıklarda, LX uygulamalarının potansiyel yeni bir yaklaşım olabileceğini destekler niteliktedir. ${ }^{29}$

Agresif periodontitis, kronik periodontitisten; hastalığın başlama yaşı, hastalığın ilerleme hızı, ilişkili subgingival mikrofloranın yapısı ve kompozisyonu, konak cevabındaki değişiklikler ve ailesel yatkınlık gibi farkllıklarıyla ayrilır. ${ }^{30}$ Generalize agresif periodontitisli hastaların DOS, salya ve serum örneklerinde ÇDYA ve metabolitlerinin değerlendirildiği bir çalışmada, İBÇLM/ proenflamatuvar lipid medyatörleri prekürsörleri oranının, sağlıkı kontrol grubuna kıyasla daha düşük seviyelerde bulunduğu gösterilmiştir. ${ }^{31}$

Lokalize agresif periodontitis (LAgP), PMNL araClı aşırı ve istenmeyen bir immün yanıtla konak dokuda şiddetli yıkıma yol açan ve daha ziyade genç bireylerde görülen periodontitis türüdür. Diğer periodontal hastalıklardan farklı olarak LAgP'de anormal konak hücre fonksiyonları bulunmaktadır. LAgP'de bölgeye aşırı PMNL toplanmasıyla ilişkili artan enflamatuvar medyatör seviyeleri, hızlı ve geniş bir doku yıkımına neden olmaktadır. PMNL aktivitesindeki artışın toksik ürün ekspresyonunu da arttırarak doku yıkımında rol alabileceği belirtilmektedir. ${ }^{32}$ LAgP'de aşırı PMNL akümülasyonunun görülmesi, PMNL'lerin bakteriyel uyaranları elimine etmede yetersiz olduğunun da bir göstergesidir.

LAgP'i bireylerden elde edilen PMNL'lerin, RvE1 uygulamasına karşı ROT üretimini azalttıkları, RvE1'in özel bir reseptör aracilı̆ıyla PMNL'lere bağlanabildiği ve ligatür ve $P$. gingivalis ile indüklenen deneysel

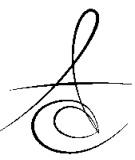


periodontitis modelinde, topikal RvE1 tedavisinin doku ve kemik kaybını oldukça önemli bir seviyede önleyebildiği rapor edilmiştir. ${ }^{33}$ Benzer bir diğer çalışmada ise, 6 hafta boyunca deneysel periodontitis oluşturulduktan sonra Rv uygulaması yapılan grupta, kontrol grubuna göre enflamasyonun tamamen çözüldüğü, sert ve yumuşak doku restorasyonun görüldüğü, dolayısıyla cep derinliğinde ve kemik içi defekt derinliğinde kontrol grubuna göre anlamlı derecede bir azalma oluştuğu gösterilmiştir. İlave olarak, periodontitis indüklenmesiyle başlangıçta tespit edilen \%30'luk kemik kaybının, kontrol grubunda \%13 arttığı fakat RvE1 tedavisiyle ise tamamen restore edildiği belirtilmiştir. ${ }^{4}$

Kronik periodontitisli hastalarda yapılan bir başka çalışmada ise, sağlıklı kontrol grubuna göre kronik periodontitisli hastalarda serum LX seviyeleri daha yüksek düzeyde tespit edilmiş, periodontal hastalığa bağı olarak artan enflamatuvar yanıtın serum LX seviyelerini yükseltebileceği ve bu yükselmenin periodontal yıkım şiddetini sınırlayabileceği öngörüsü üzerinde durulmuştur. ${ }^{34}$

\section{SONUÇ}

Enflamatuvar yanıtın temel amacl, dokunun homeostazise dönmesini etkileyen faktörleri tespit etmek ve ortamdan uzaklaştırmaktır. Mikrobiyal dental plak içerisinde yer alan patojenlere karşı ilk cevap, epitel içerisinde başlayıp, çeşitli sitokin, kemokin ve proenflamatuvar lipid medyatörlerinin sentezinin arttırılması ve dolaşımdaki lökosit ve akut faz proteinlerinin uyarılmasıyla birlikte sistemik yanıta doğru ilerler. Dokunun homeostazise dönememesi sonucunda, PMNL aracılı yıkım ve kronik enflamasyon meydana gelmektedir. Periodontal hastalık patogenezinde de, kontrol altına alınamamış enflamatuvar cevabın, hastalığın oluşması ve ilerlemesinde temel faktör olduğu belirtilmiştir. ${ }^{29} \mathrm{Bu}$ anlamda 20. yüzyılda enflamasyonla ilişkili yapılan en önemli keşfin, enflamasyonun çözülmesinde rol alan moleküllerin ortaya çıkarılması olduğu düşünülmektedir. ${ }^{35}$

Periodontal hastalıklar, enflamatuvar olaylar kaskadını düzenleyen bir seri konak yanıtının indüklemesi sonucunda oluşmaktadır. Diğer taraftan periodontal hastalığın ilerlemesi ve kardiyovasküler hastalık, diyabet ve hiperlipidemi gibi diğer sistemik hastalıklarla birlikte genellenmesi, patogenezin altında yatan enflamatuvar olaylara dayanmaktadır. Enflamasyonun yeni terapötik yaklaşım şekli olan İBÇLM'lerle çözülmesi, aşırı hücresel aktivitenin de baskılanabilmesi yönüyle, konak modülasyonunda kullanılan proenflamatuvar sitokin antagonistleri gibi geleneksel yöntemlere göre net bir avantaj sağlamaktadır.

\section{KAYNAKLAR}

1. Kantarci A, Hasturk H, Van Dyke TE. Hostmediated resolution of inflammation in periodontal diseases. Periodontol 2000 2006;40:144-63.

2. Khanna S, Biswas S, Shang Y, Collard E, Azad A, Kauh C, Bhasker V, Gordillo GM, Sen CK, Roy S. Macrophage dysfunction impairs resolution of inflammation in the wounds of diabetic mice. PLoS One 2010;5:e9539.

3. Hutchinson JL, Rajagopal SP, Sales KJ, Jabbour $\mathrm{HN}$. Molecular regulators of resolution of inflammation: potential therapeutic targets in the reproductive system. Reproduction 2011;142:1528.

4. Hasturk $H$, Kantarci A, Goguet-Surmenian $E$, Blackwood A, Andry C, Serhan CN, Van Dyke TE. Resolvin $\mathrm{E} 1$ regulates inflammation at the cellular and tissue level and restores tissue homeostasis in vivo. J Immunol 2007;179:7021-9.

5. Bhatavadekar NB, Williams RC. Modulation of the host inflammatory response in periodontal disease management: exciting new directions. Int Dent J 2009;59:305-8.

6. Serhan CN, Chiang N, Van Dyke TE. Resolving inflammation: dual anti-inflammatory and proresolution lipid mediators. Nat Rev Immunol 2008;8:349-61.

7. Southerland JH, Taylor GW, Moss K, Beck JD, Offenbacher S. Commonality in chronic inflammatory diseases: periodontitis, diabetes, and coronary artery disease. Periodontol 2000 2006;40:130-43.

8. Serhan CN, Brain SD, Buckley CD, Gilroy DW, Haslett C, O'Neill LA, Perretti M, Rossi AG, Wallace JL. Resolution of inflammation: state of the art, definitions and terms. FASEB J 2007;21:325-32.

9. Van Dyke TE. The management of inflammation in periodontal disease. J Periodontol 2008;79:1601-8. 
10. Serhan CN. Novel lipid mediators and resolution mechanisms in acute inflammation: to resolve or not? Am J Pathol 2010;177:1576-91.

11. Grover V, Malhotra R, Kapoor A, Singh J, Sachdeva S. Proresolution mediators and receptors: novel drug targets for enhancing pharmacological armamentarium against periodontal inflammation. Infect Disord Drug Targets 2013;13:75-84.

12. Schwab JM, Chiang N, Arita M, Serhan CN. Resolvin $\mathrm{E} 1$ and protectin D1 activate inflammation-resolution programmes. Nature 2007;447:869-74.

13. Freire-de-Lima CG, Xiao YQ, Gardai SJ, Bratton DL, Schiemann WP, Henson PM. Apoptotic cells, through transforming growth factor-beta, coordinately induce anti-inflammatory and suppress pro-inflammatory eicosanoid and NO synthesis in murine macrophages. J Biol Chem 2006;281:38376-84.

14. Serhan CN, Hong S, Gronert K, Colgan SP, Devchand PR, Mirick G, Moussignac RL. Resolvins: a family of bioactive products of omega-3 fatty acid transformation circuits initiated by aspirin treatment that counter proinflammation signals. ] Exp Med 2002;196:1025-37.

15. Hong S, Gronert K, Devchand PR, Moussignac RL, Serhan CN. Novel docosatrienes and 17S-resolvins generated from docosahexaenoic acid in murine brain, human blood, and glial cells. Autacoids in anti-inflammation. J Biol Chem 2003;278:1467787.

16. Campbell EL, Louis NA, Tomassetti SE, Canny GO, Arita M, Serhan CN, Colgan SP. Resolvin E1 promotes mucosal surface clearance of neutrophils: a new paradigm for inflammatory resolution. FASEB J 2007;21:3162-70.

17. Rock $\mathrm{KL}$, Kono $\mathrm{H}$. The inflammatory response to cell death. Annu Rev Pathol 2008;3:99-126.

18. Bannenberg $G L$, Chiang $N$, Ariel A, Arita $M$, Tjonahen $\mathrm{E}$, Gotlinger $\mathrm{KH}$, Hong $\mathrm{S}$, Serhan $\mathrm{CN}$. Molecular circuits of resolution: formation and actions of resolvins and protectins. J Immunol 2005; 174:4345-55.

19. Haworth O, Cernadas M, Yang R, Serhan CN, Levy $B D$. Resolvin $E 1$ regulates interleukin 23, interferon-gamma and lipoxin A4 to promote the resolution of allergic airway inflammation. Nat Immunol 2008;9:873-9.
20. Levy BD, Clish CB, Schmidt B, Gronert K, Serhan CN. Lipid mediator class switching during acute inflammation: signals in resolution. Nat Immunol 2001;2:612-9.

21. Fierro IM, Serhan CN. Mechanisms in antiinflammation and resolution: the role of lipoxins and aspirin-triggered lipoxins. Braz J Med Biol Res 2001;34:555-66.

22. Birkedal-Hansen $H$. Role of cytokines and inflammatory mediators in tissue destruction. ] Periodontal Res 1993;28:500-10.

23. Fiorucci S, Distrutti E, Mencarelli A, Rizzo G, Lorenzo AR, Baldoni M, Del Soldato P, Morelli A, Wallace JL. Cooperation between aspirin-triggered lipoxin and nitric oxide (NO) mediates antiadhesive properties of 2-(Acetyloxy)benzoic acid 3(nitrooxymethyl)phenyl ester (NCX-4016) (NOaspirin) on neutrophil-endothelial cell adherence. J Pharmacol Exp Ther 2004;309:1174-82.

24. Pouliot $M$, Clish CB, Petasis NA, Van Dyke TE, Serhan CN. Lipoxin $A(4)$ analogues inhibit leukocyte recruitment to Porphyromonas gingivalis: a role for cyclooxygenase-2 and lipoxins in periodontal disease. Biochemistry 2000;39:4761-8.

25. Pham K, Feik D, Hammond BF, Rams TE, Whitaker EJ. Aggregation of human platelets by gingipain-R from Porphyromonas gingivalis cells and membrane vesicles. Platelets 2002;13:21-30.

26. Sharma A, Novak EK, Sojar HT, Swank RT, Kuramitsu HK, Genco RJ. Porphyromonas gingivalis platelet aggregation activity: outer membrane vesicles are potent activators of murine platelets. Oral Microbiol Immunol 2000;15:393-6.

27. Borgeson E, Lonn J, Bergstrom I, Brodin VP, Ramstrom S, Nayeri F, Sarndahl E, Bengtsson T. Lipoxin $A(4)$ inhibits porphyromonas gingivalisinduced aggregation and reactive oxygen species production by modulating neutrophil-platelet interaction and CD11b expression. Infect Immun 2011;79:1489-97.

28. Serhan CN, Jain A, Marleau S, Clish C, Kantarci A, Behbehani B, Colgan SP, Stahl GL, Merched A, Petasis NA, Chan L, Van Dyke TE. Reduced inflammation and tissue damage in transgenic rabbits overexpressing 15-lipoxygenase and endogenous anti-inflammatory lipid mediators. ] Immunol 2003;171:6856-65. 
29. Kantarci A, Van Dyke TE. Lipoxins in chronic inflammation. Crit Rev Oral Biol Med 2003;14:4-12.

30. Yıldırım TT, Kaya FA. Agresif Periodontitis. Atatürk Üniv Diş Hek Fak Derg 2011;4:15-23.

31. Elabdeen HR, Mustafa M, Szklenar M, Ruhl R, Ali R, Bolstad AI. Ratio of pro-resolving and proinflammatory lipid mediator precursors as potential markers for aggressive periodontitis. PLoS One 2013;8:e70838.

32. Kantarci A, Oyaizu K, Van Dyke TE. Neutrophilmediated tissue injury in periodontal disease pathogenesis: findings from localized aggressive periodontitis. J Periodontol 2003;74:66-75.

33. Hasturk $H$, Kantarci A, Ohira $T$, Arita M, Ebrahimi $N$, Chiang N, Petasis NA, Levy BD, Serhan CN, Van Dyke TE. RvE1 protects from local inflammation and osteoclast- mediated bone destruction in periodontitis. FASEB J 2006;20:401-3.

34. Dogan B, Fentoglu O, Kirzioglu FY, Kemer ES, Koroglu BK, Aksu O, Carsancakli SA, Orhan H. Lipoxin A4 and Neutrophil/Lymphocyte Ratio: A Possible Indicator in Achieved Systemic Risk Factors for Periodontitis. Med Sci Monit 2015;21:2485-93.

35. Freire MO, Van Dyke TE. Natural resolution of inflammation. Periodontol 2000 2013;63:149-64.

\section{Yazışma Adresi}

Dr. Burak Doğan,

Mustafa Kemal Üniversitesi,

Diş Hekimliği Fakültesi,

Periodontoloji Anabilim Dalı, 31100, Antakya/Hatay, Türkiye.

Tel: 03262456060/3154

e-posta: burakdogann@gmail.com fax: 03262455060 